Recebido: $25 / 12 / 2015$

Aprovado: 26/01/2016

\title{
Narrativas e jogos de interpretação (RPG): possibilidades historiográficas ou desafios literários?
}

Jorge Artur Caetano Lopes dos Santos ${ }^{1}$

Resumo: Os jogos de interpretação ou role playing games (RPG) introduzem um elemento significativo para o ensino de história: formas de se imaginar as coisas como elas podem ter sido. Através das narrativas, é possível pluralizar o entendimento sobre o passado e as relações com a cultura histórica. $O$ objetivo do presente artigo é refletir sobre a relação entre narrativa, história e jogos de interpretação.

Palavras-chave: História; Narrativa; RPG.

Abstract: Role playing games (RPG) introducing a significant element in history teaching: ways to imagine things as they might have been. Through narratives, it is possible to pluralize the understanding of the past and the relations with the historical culture. The purpose of this article is to think about the relationship between narrative, history and role playing games.

Keywords: History; Narrative; RPG.

1 Doutorando em História do programa de pós-graduação da Universidade de Brasília. E-mail: salvejorge@gmail.com 
Ser ou não ser, eis a questão.

Hamlet, William Shakespeare

\section{Introdução: que comece a narrativa}

“O Jorge sempre sexualisa os meus personagens" foi a fala do jogador Thiago Pereira Perpétuo no jogo de domingo, 15/11/2015. Seu personagem em questão é um garoto chamado Auron Bethan, de 17 anos, nascido e crescido em uma pequena vila de pescadores chamada Soubar, onde tem início a trama. O próprio jogador, ao narrar a vida anterior ao jogo do personagem, destaca que:

Auron Bethan levou uma vida discreta e, tanto quanto podia, pacata. Senão por uma ou outra briga relacionada com o falatório a respeito do infortúnio de sua família. As línguas mais ferinas atribuíam a desgraça dos Bethan a uma maldição que recaía sobre os homens da família, "Nada de bom pode vir de uma casa de homens..." diziam alhures; outros, afirmavam que se tratava de falta de tributos e honras aos deuses do mar e das montanhas. Mas alguns, os mais hostis, diziam que fora culpa da senhora ao sopé da montanha, a bruxa dos unguentos, cuja atribuição de parentesco ou qualquer relação de proximidade era tido como uma ofensa grave entre os habitantes da vila - mesmo os que se valiam de seus unguentos para curas eventuais. Vez por outra Auron brigava. Jamais se teve notícia de ter vencido uma luta sequer.

O objetivo dessa pequena biografia inicial é criar uma história para o personagem em um jogo de interpretação ou role playing game (RPG), algo para além dos números e atributos da ficha do personagem. O objetivo do presente texto é refletir sobre a relação entre narrativa e jogos de interpretação, e para tanto, destacar alguns momentos narrativos da constituição dos jogos de interpretação. Penso agora em pelo menos quatro momentos onde há dividendos quanto às possibilidades para pensar a narrativa: na construção do personagem; nas falas "do personagem" em meio à interpretação; na relação com o resultado dos dados; nas negociações entre os jogadores "fora" do jogo.

Minha referência à prática dos jogos de interpretação envolverá experiências próprias de jogo, elas mesmas tributárias de observações e leituras. Faço parte de um grupo de oito pessoas que jogam semanalmente desde 1999, tendo sido produzido um material também semanal sobre os jogos de nossas duas últimas campanhas no blog Possibilidades ${ }^{2}$, ainda que esteja ali a minha narrativa sobre o jogo. Além disso, tenho um jogo de interpretação por e-

\footnotetext{
${ }^{2} \mathrm{O}$ material dos jogos pode ser consultado em http://yorgoi.blogspot.com.br/.
} 
mail chamado Desafio Literário, do qual já tomaram parte mais de cem pessoas ao longo de quase dez anos, mas que hoje conta com três jogadores regulares. O material desse jogo vem sendo publicado no blog Desafio Literário ${ }^{3}$.

É importante explicar aqui que existem várias modalidades, sistemas de regras e cenários de jogo. As modalidades envolvem a forma pela qual se construirá a narrativa do jogo, quais os parâmetros da interação entre jogadores e os meios dessa interação. Os sistemas de regras são as leis que governam o funcionamento do jogo dentro da modalidade escolhida. Os cenários são as ambientações possíveis.

Entre as modalidades de jogo, a mais tradicional é o jogo de mesa, onde os jogadores destacam um mestre do jogo, que proporá os desafios, enquanto os demais atuam com seus personagens. Os personagens são descritos em fichas de personagens e anotações, havendo muitas vezes miniaturas e campos de batalha, que são uma herança de jogos de tabuleiro que estão na formação desses jogos.

Os chamados "live actions" são uma modalidade de jogo onde os jogadores passam a maior parte do tempo imersos nos personagens como em um teatro de improvisos. Muitas vezes, ela exige mais mestres para coordenar a ação e tem momentos marcados como fora do jogo para montar o cenário das atuações. As fichas e dados tem um papel muito menor, havendo uma preocupação com a caracterização através de vestimentas, maquiagem e apetrechos.

Os jogos literários são feitos através de pequenos textos trocados entre duas ou mais pessoas. O desenvolvimento da internet teve importante papel na difusão desse tipo de jogo, facilitando a troca de mensagens. Nessa modalidade, o jogo acaba tomando a forma de um livro escrito a muitas mãos, embora seja costume destacar um mestre que coordena os textos produzidos.

Existe ainda a modalidade de jogo individual, em que há pouco espaço para analisar a interpretação por não haver interação direta com outros jogadores. Marcada pela época dos livros-jogos, depois pelas aventuras textuais nos primórdios da internet, essa modalidade teve significativa influência na formação dos RPGs de videogames. Nesse incrível mercado dos videogames, no entanto, a própria individualidade do jogo consegue ser imersa no mar de contatos da rede mundial com os Massive Multiplayers Online RPGs ou MMORPGs. De qualquer forma, ainda existem muitas possibilidades a serem exploradas nessa relação como destacam Araújo e Ramalho (ARAÚJO \& RAMALHO, 2015).

\footnotetext{
${ }^{3} \mathrm{O}$ material dos jogos pode ser consultado em http://rpgdesafioliterario.blogspot.com.br/.
} 
Os sistemas de regras para os jogos de interpretação muitas vezes estão associados a um tipo de dado, a alguma editora e / ou a grupos de adeptos. Alguns sistemas tradicionais e identificados pelo dado mais utilizado na mecânica são o d20, o d10 e o d6, respectivamente ligados aos jogos Dungeons\&Dragons (D\&D), World of Darkness (WofD) e GURPS ${ }^{4}$. Na verdade, existe uma infinidade de sistemas e nem todos usam dados como é o caso de Castelo Falkenstein, que trabalha com cartas de baralho, bem como live actions, onde os conflitos são resolvidos com rápidas disputas de pedra-papel-tesoura.

O importante a destacar sobre os sistemas de regras é que eles são responsáveis por garantir a mecânica do jogo determinando os parâmetros de como montar os personagens dos jogadores, do que são sucessos, fracassos e as diretrizes para as ações. A ideia é resolver disputas ou associações entre os jogadores e entre seus personagens e o ambiente. Ainda que toda e qualquer regra de um sistema possa ser alterada de acordo com regras opcionais do próprio sistema, regras "da casa" de cada grupo ou mesmo em situações específicas da mesa de jogo, elas não deixam de ser uma referência articuladora do jogo. A regra de ouro para vários sistemas é garantir a diversão de todos os envolvidos.

Mais diversos ainda são os cenários de jogo, as ambientações onde esses sistemas podem ser aplicados. Apenas as cinco edições do célebre sistema Dungeons\&Dragons ocuparam-se de criar vinte e quatro cenários entre regiões, mundos, dimensões, universos, etc. Existem desde ambientes de fantasia medieval como os reinos esquecidos de Forgotten Realms $^{5}$ até o horror fatalista das brumas de Ravenloft. É tarefa simples encontrar muitas referências históricas, como as formas de imaginar o medievo das chamadas "fantasias medievais", a Era Vitoriana de Castelo Falkenstein ou mesmo a contemporaneidade decadente do World of Darkness.

Mas é certo também que os cenários possuem marcada influência de inúmeras obras literárias como O Senhor dos Anéis, Drácula, Duna, entre tantas outras, assim como de filmes, animações, programas de televisão, quadrinhos, entre outros. Muitas vezes as editoras buscam adaptar diretamente cenários pré-existentes na literatura, na televisão ou no cinema como é o caso dos jogos O Senhor dos Anéis, The Walking Dead, Call of Cthulhu ou Game of Thrones. A proposta desses cenários é inserir os jogadores num ambiente com o qual já tem

\footnotetext{
${ }^{4} \mathrm{Na}$ verdade, o Generic and Universal Role Playing System (GURPS) é apenas um dos muitos sistemas de jogo que fazem uso do dado de 6 faces (d6) como base, outros exemplos são Earthdawn e o brasileiro 3D\&T.

${ }^{5} \mathrm{O}$ mundo de Forgotten Realms é chamado Abeir-Toril e compreende quarto cenários de jogo: Faerun, Kara Tur, Al Qadim e Maztica, cada qual com suas características próprias, mas que correspondem grosso modo à Europa, Extremo Oriente, Oriente Médio e a América pré-colombiana respectivamente.
} 
certa familiaridade, interagindo com a trama das obras de referência na maioria dos casos. Ainda assim, mesmo essas referências também se pautam por significar o passado com suas pitadas de história.

Além de cada editora produzir dezenas de lugares para que os jogadores possam se apropriar com sua imaginação, há ainda o incentivo a que os próprios jogadores desenvolvam um mundo para chamarem de seu. Boa parte dos compêndios de regras dedica-se a estabelecer quais parâmetros seguir para criar uma cidade, uma região, um mundo ou todo um universo e povoá-lo, o que também está submetido à regra de ouro do jogo: diversão. Se por um lado cidades voadoras podem pulverizar as leis mais básicas da física, por outro, um realismo mortal pode estar em cada golpe de punhal ou intriga da corte se for essa a diversão buscada pelo grupo de jogadores.

Dessa forma, na minha opinião, o RPG introduz um elemento significativo para o ensino, por exemplo, de história: formas de se imaginar as coisas como elas podem ter sido, uma vez que isso também é o melhor que a história pode fazer por nós. Não se trata de substituir a história por ficções divertidas, mas sim, através das narrativas, pluralizar o entendimento sobre o passado. Nas palavras de Linda Hutcheon, é preciso entender que "a ficção e a história são discursos, que ambas constituem sistemas de significação pelos quais damos sentido ao passado" (HUTCHEON, 1991: 122). Os jogos de interpretação se apresentam como uma possibilidade de lidar com esses sistemas, de operacionalizá-los desde que entendamos que não se excluem, mas sim dialogam.

É evidente que jogos de interpretação têm uma dimensão fantástica que atrai os jogadores seja para cortar a cabeça de um orc, transformar-se em um morcego, lançar uma bola de fogo pelos ares ou simplesmente ser outrem em outro lugar. Mas mesmo isso pode ser campo para narrativas historiográficas. A espada que cortará um orc é uma criação a partir de representações de armas do passado. As características de um monstruoso zumbi morto-vivo também vão se referenciar no que se pensou sobre isso no passado e servem até mesmo para pensar se verdadeiros monstros não são os vivos sobreviventes no apocalipse zumbi. Os poderes do vampiro nos remetem a Bram Stoker e seu Drácula, que "embora tenha se inspirado em autores anteriores, jamais alguém antes pintara um quadro com semelhante riqueza" (LECOUTEUX, 2005: 10). De acordo com Claude Lecouteux, vários outros autores, "grandes nomes assinaram histórias de vampiros: Prosper Mérimée (1827), com La guzla, Baudelaire, Byron. Coleridge, Felix Dahn, Alexandre Dumas, Hans Heinz Ewers e Theóphile Gautier, para citar apenas alguns" (LECOUTEX, 2005: 10). Além destes, o autor lista 650 
filmes e 250 sítios na internet com material sobre o tema. Mas para Lecouteux, é fundamental destacar que:

O que abona a crença nos vampiros, o que tem provocado o fluxo de tratados eruditos, são os relatórios de autoridades, como aquele publicado em Belgrado, em 1732, pelo tenente-coronel Büttener e J. H. von Lindenfels sobre os vampiros da cidade sérvia de Medvegia, ou aquele publicado no mesmo ano, em Berlim, pela Sociedade Real Prussiana de Ciências. Os eruditos tiraram daí as informações que comentaram infinitamente e, em 1746, dom Augustin Calmet, monge beneditino de Senonos, fez a síntese dos estudos sobre o assunto na sua Dissertação sobre as aparições dos espíritos e sobre os vampiros ou fantasmas da Hungria, Morávia (LECOUTEUX, 2005: $13)$.

Não só há um diálogo claro entre o aparecimento dos chamados seres das trevas no Século das Luzes, como entre história e ficção na configuração de um imaginário sobre essas criaturas. Pensemos aqui no imaginário como o "dinamismo organizador" de que nos fala Bachelard (Cf. BACHELARD, 1974). Talvez isso ganhe vulto se pensarmos ao invés de fantásticos vampiros imortais em um mortal sans-cullote francês da Paris pré-Revolução. Não dialogaremos aqui com a historiografia, a literatura, o cinema, entre outros, para imaginarmos esse personagem? "O sans-culotte parisiense (também presente no restante do país) se vê como representante do povo mobilizado em defesa da Revolução" nos explica Michel Vovelle ao narrar a Revolução Francesa para sua neta. O historiador prossegue a caracterização desses personagens dizendo que:

A roupa deles é diferente: em vez do calção até o joelho e das meias usadas pelos burgueses e aristocratas, eles vestem uma calça (geralmente listrada) e daí o apelido, inicialmente depreciativo, mas que depois será motivo de orgulho para eles. Vestem também um pequeno colete, a carmanhola, e trazem na cabeça o barrete frígio (uma boina vermelha) da liberdade com a insígnia. (...) Ia me esquecendo: falta, na descrição, o sabre e o pique, uma lança com ponta de metal (VOVELLE, 2007: 65).

Essa é certamente uma caracterização bem diferente da que faz Edmund Burke em sua análise dos revolucionários franceses: "um bando de rufiões e assassinos", armados com "baioneta e punhal", que desfilam com "cabeças fincadas em lanças que tomaram a frente do cortejo, enquanto os prisioneiros reais as seguiam lentamente, no meio de gritos horrorosos, urros assustadores, danças frenéticas" (BURKE, 1997: 97).

Desse modo, a historiografia, a análise de documentos, assim como as mitologias, as epopeias e a literatura de forma geral podem ter nisso importante papel, uma vez que todas 
integram de forma múltipla a nossa cultura histórica. De acordo com Rachel Soihet, devemos pensar uma "cultura histórica" como "relação que uma sociedade mantém com seu passado" (SOIHET, 2009: 84). Os textos históricos trazem sentidos significativos a esse exercício de imaginar e representar, pois nas palavras de François Hartog "também a história pode ser tratada como (e não reduzida a) um texto" (HARTOG, 1998: 201). Assim como não há texto historiográfico que escape as dimensões narrativa e ficcional dos textos (WHITE, 2000), não há texto que deixe de ter uma dimensão histórica na sua tessitura.

\section{Narrativa e construção dos personagens}

Para pensarmos a narrativa e os jogos de interpretação é preciso explicitar melhor o que entendemos por narração. De acordo com Monika Fludernik, a narrativa é uma estrutura epistemológica fundamental que produz padrões explanatórios. Para essa autora:

Narrativa é uma representação de um mundo possível em um meio linguístico e/ou visual, no centro do qual há um ou vários protagonistas de natureza antropomórfica que estão existencialmente ancorados em um senso temporal e espacial e que (em geral) realizam ações direcionadas a metas (estruturas de ação e enredo). É a experiência desses protagonistas que a narrativa foca, permitindo aos leitores ficarem imersos num mundo diferente e na vida dos protagonistas (FLUDERNIK, 2009: 6).

Essa definição de narrativa poderia muito bem ser uma definição do que é um jogo de interpretação, que também trata de representar mundos possíveis em meios linguísticos e visuais, com protagonistas antropomórficos num espaço e num tempo e que realiza ações visando metas. Nas narrativas dos jogos, no entanto, não apenas os leitores acompanham os personagens, mas sim os criam e interpretam todo o tempo, estando imersos em seu mundo e em suas experiências. Assim como o escritor assume a forma de um "storyteller" nas narrativas em torno de um enredo, nos RPGs esse papel pode caber a um jogador específico (o dungeon master, storyteller ou simplesmente mestre do jogo) ou a todos os jogadores em conjunto.

Outra possibilidade para pensarmos o conceito de narrativa é a de Marie-Laure Ryan. Para essa autora não interessa uma definição tão direta de narrativa como a de Fludernick, mas sim uma definição de círculos concêntricos de condições de narratividade, ou seja, elementos que adensam ou dispersam o quão narrativo é um texto. De acordo com Ryan:

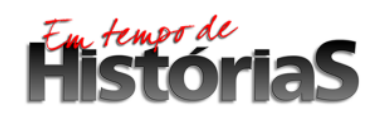


A proposta abaixo organiza as condições de narratividade em três dimensões semânticas e uma formal e pragmática.

\section{Dimensão espacial}

(1) Narrativa tem que ser sobre um mundo povoado por existentes individuados.

\section{Dimensão temporal}

(2) Esse mundo tem que ser situado no tempo e passar por transformações significativas.

(3) As transformações tem que ser causadas por eventos físicos não habituais.

\section{Dimensão mental}

(4) Alguns dos participantes no evento tem que ser agentes inteligentes que tenham uma vida mental e reajam emocionalmente aos estados do mundo.

(5) Alguns dos eventos têm que ser ações propositais desses agentes.

\section{Dimensão formal e pragmática}

(6) A sequência dos eventos tem que formar uma corrente causal unificada e conduzir ao encerramento.

(7) A ocorrência de pelo menos alguns dos eventos tem que ser afirmada para a história-mundo.

(8) A história tem que comunicar algo significativo para a audiência (RYAN, 2007: 29).

Os jogos de interpretação sempre atendem a maior parte das condições: se passam em mundos povoados (1), passam por transformações (2), todos os participantes são agentes inteligentes (4), os eventos são ações desses agentes (5), existe uma corrente causal de acontecimentos (6) e a história é significativa para a audiência (8). Além dessas, transformações causadas por eventos não habituais (3) e a afirmação de eventos para a história-mundo (7) são constantes embora não imprescindíveis. Portanto, também há sintonia entre tal conceituação e uma percepção da relação entre narrativa e jogos de interpretação.

Quando cada um dos jogadores vai construir o seu personagem, isso passa por preencher uma ficha com os dados do personagem, mas mais do que isso, passa por criar uma narrativa que o levou até o ponto inicial do jogo. É preciso entender que qualquer que seja a roupagem, o personagem é sempre uma representação do jogador. Mesmo em casos onde são selecionados personagens com estatísticas dadas ou pré-estabelecidas, ainda assim, ao "dar vida ao personagem", o jogador o torna uma representação de si mesmo. Nessa narrativa, o protagonista já está dado antes da montagem do personagem.

Ainda assim, por outro lado, há sempre algo de novo, algo de criativo nessa representação, afinal de contas, como nos lembra Hayden White, "a representação de uma 
coisa não é a própria coisa" (WHITE, 2000: 397). É a prática do jogo e a narrativa que vai sendo construída entre os jogadores que vão dando substância ao personagem com base nas escolhas do jogador e nas experiências, não apenas o jogador enquanto referência. O filósofo Paul Ricoeur nos explica que "a representação enquanto narração não se volta ingenuamente para as coisas ocorridas; a forma narrativa enquanto tal interpõe sua complexidade e sua opacidade próprias ao que gosto de chamar de pulsão referencial da narrativa histórica" (RICOEUR, 2012: 250). Desse modo, voltando ao exemplo inicial, ainda que o jogador Thiago construa uma narrativa biográfica sobre Auron, onde tudo que o define são seus próprios interesses, são as situações de interação narrativa que constituirão os caminhos e descaminhos do personagem. No limite, isso se dá quando o jogador se vê "obrigado" a tomar decisões que não gostaria, mas que interessam à narrativa do personagem.

Portanto, a construção do personagem é um processo ininterrupto onde há uma aproximação entre autor e narrador como nos sistemas de ficcionalização conforme as ideias de Phillipe Carrard (CARRARD: 2012). O jogador surge como autor e narrador de seu personagem, tendo liberdade de dar conta do enredamento dessa narrativa. Ainda que esse processo possa se dar em consonância com o trabalho dos colegas jogadores, essa microhistória mais facilmente articula uma "homogeneidade significante" (LOPES, 2015: 112). Conflitos, tensões e descontinuidades podem ser aplainados no intuito de amarrar as possibilidades no rumo certo que garantirá a entrada do personagem na ação vindoura da trama coletiva, bem como reviravoltas, resistências e continuidades podem se afirmar na corrente causal do jogo de interpretação.

Também é interessante destacar aqui a dimensão narrativa do discurso histórico. Roger Chartier defende a "plena pertença da história, em todas as suas formas, mesmo as mais estruturais, ao domínio da narrativa" (CHARTIER, 1990: 81). O historiador francês não entende haver espaço para pensar um "ressurgimento da narrativa", conforme a expressão de Lawrence Stone em seu artigo (STONE, 1979) e o ideário dos praticantes da chamada história-problema defendida pelos membros da escola dos Annales. Para Chartier, "a história é sempre relato, mesmo quando pretende desfazer-se da narrativa, e o seu modo de compreensão permanece tributário dos procedimentos e operações que assegurem a encenação em forma de intriga das ações representadas" (CHARTIER, 1990: 82).

O historiador Roger Chartier dialoga com as ideias desenvolvidas por Paul Ricoeur, que tanto refletiu sobre a narrativa historiográfica. Hartog destaca que "Paul Ricoeur, cioso de sondar o mistério do tempo, considera sucessivamente a história e a ficção e chega à 
conclusão de que não poderia haver história sem elo, por tênue que seja, com a narrativa" (HARTOG, 1998: 194). Mais do que apenas destacar a inevitável dimensão narrativa da história, esse autor valoriza seus efeitos. De acordo com José D’Assunção Barros:

A consciência da narratividade (necessária) da História, reafirmada por Paul Ricoeur, apresenta implicações importantes, sendo a mais importante delas assegurar o retorno do vivido, da sensibilidade e da ação humana a uma historiografia que nos casos extremos parecia quase se abstrair do homem (BARROS, 2011: 3).

\section{Narrativa e as falas "do personagem"}

- Ahhh! Quem é você?

- Shhh! Seu idiota! Você quer que eles venham aqui e saibam com que tipo de gente você está se metendo?

- Eu não estou me metendo com gente... Eu não estou me metendo com gente nenhuma? Você não é gente. De... De que você está falando?

- Eu sou Urnão, eu sou filho dos dragões, assim como você, seu idiota.

Esse pequeno diálogo se deu no mesmo jogo do domingo, 15/11/2015, entre um personagem não-jogador controlado por mim e o já citado personagem Auron do jogador Thiago. Ele teve início assim que descrevi a criatura que o personagem havia visto ao se virar no próprio quarto. Foi interrompido quando o jogador anunciou que estava se beliscando para ver se não estava sonhando. Durante esse curto recorte, há uma forma particular de narrativa no jogo de interpretação.

Há um momento onde a narrativa individual de cada jogador perturba a narrativa coletiva que vai sendo urdida: quando ele dá voz ao personagem com suas próprias palavras. Nesse momento, o jogador deixa de se referir ao personagem na $3^{\mathrm{a}}$ pessoa e passa a encenar diretamente, verbalizar o pensamento do personagem. Temos aqui uma representação tanto como encenação, quanto como substituição de um ausente que torna sensível uma presença. Ou seria mais apropriado pensarmos em uma performance?

Guardadas as distinções para a encenação teatral, acredito que acrescenta à reflexão a observação de Kalle Pihlainen de que "tomar a ação no palco como ação que está criando ao invés de simplesmente re-criando algo é o mais perto que parece podermos chegar em negar a representação na performance" (PIHLAINEN, 2002: 192). Sob tal ótica, nesse momento do jogo de interpretação podemos acreditar que a narrativa que transborda dos lábios e gestos do jogador é algo único em si mesmo e não um trazer de volta à vista, um re-apresentar. 
No entanto, se buscarmos uma noção de uma representação amparada na mímesis, defendida por autores como Roger Chartier e Paul Ricoeur, podemos pensar que essa narrativa está sim interessada em encenar o retorno à cena de uma certa coerência, de uma homogeneidade pretendida. Chartier acredita que "considerar, acertadamente, que a escrita da história pertence à classe das narrativas não equivale a considerar como ilusória sua intenção de verdade, de uma verdade considerada como representação adequada daquilo que foi” (CHARTIER, 1995: 193). Por sua vez, Paul Ricoeur acrescenta que "a representação historiadora é de fato uma imagem presente de uma coisa ausente; mas a própria coisa ausente desdobra-se em desaparição e existência no passado" (RICOEUR, 2012: 294).

É certo que os jogos de interpretação não têm uma intenção de verdade ou que os personagens sejam mais ausentes do que imaginados. Porém, a construção do jogo e do personagem a cada jogo vai criando uma massa de experiências que como "a tradição de todas as gerações mortas oprime como um pesadelo o cérebro dos vivos” (MARX, 2015: 6), os jogadores. Dessa forma, estes buscam uma representação adequada daquilo que pode ser, uma imagem presente de uma coisa ausente.

Embora isso possa parecer contraditório, acredito haver espaço para uma representação do personagem assim como uma performance do personagem. Há substituição de um ausente ao mesmo tempo que há criação nesse momento da narrativa no jogo. Além disso, tanto acho que as narrativas construídas nos atos de fala enquadram-se na determinação conceitual de Fludernik ou na maior parte das condições de Ryan (ao menos 1, 2, 4, 5 e 8).

\section{Narrativa e o resultado dos dados}

- Dragões, dragões!!! Ela é uma dragoa.

- Vem cá. Esse branco... São todos eles brancos, Isobel?

- Não, tem várias cores.

- E o que elas querem dizer?

- Eu acho que a cor é só um detalhe. Não existem pessoas de cabelo preto e cabelo loiro? Tanto faz.

Esse diálogo acima transposto se deu no jogo do domingo, 06/12/2015, entre os jogadores Thiago e Daphne Kipman, que interpretavam respectivamente Auron e Isobel McEwan. Os dois discutiram o surgimento de um colossal dragão branco no pico da montanha que escalavam. O jovem Auron, que possui sangue de dragões e por isso é um feiticeiro, desejava respostas sobre a criatura, enquanto a sábia e curandeira Isobel 
representava o fraco desempenho de sua rolagem de dado, onde teve um fracasso, pois tirou $1^{6}$. Ainda que a jogadora Daphne saiba que a cor dos dragões dentro das regras do sistema está diretamente ligada às suas características, poderes, habitat e comportamento, ela viu-se obrigada a dar voz ao entendimento limitado que os dados impuseram à personagem.

Se Albert Einstein disse que "Deus não joga dados com o universo", nos jogos de interpretação, os dados são uma maneira tradicional de lidar com o elemento aleatório das vivências dos personagens. Ainda que caiba ao jogador encenar o peso dos dados, eles surgem aqui como um fator condicionante das narrativas a serem construídas. É preciso pensar tanto as brechas e táticas dos jogadores para se apropriar do que os dados tentam determinar, quanto o recurso aos dados quando as próprias ideias do jogador para resolver situações parecem faltar.

É possível percebermos a narrativa construída a partir do resultado dos dados como parte desses "procedimentos - multiformes, resistentes, astuciosos e teimosos - que escapam à disciplina sem ficarem mesmo assim fora do campo onde se exerce, e que deveriam levar a uma teoria das práticas cotidianas" de que fala Michel de Certeau (CERTEAU, 2014: 163). Afinal de contas, o resultado do dado não passa de um número balizado pelas regras do sistema e não existe regra que seja total e escape a subjetivações. É a performance do jogador que vai transformar aquilo numa narrativa que representa mais que um número.

Ao analisar as narrativas posteriores ao rolar dos dados, estas também atendem aos parâmetros de Fludernik ao se apresentar em representações de pequenos mundos possíveis e imediatos, através de meios linguísticos e visuais. Narrativas que seguiriam seus personagens no realizar de ações visando metas, entre falhas e sucessos. O mesmo é possível dizer sobre as condições de Ryan.

Tudo isso me faz pensar, no entanto, que a relação entre o resultado dos dados e a narrativa não seja exatamente um momento da questão da narrativa nos jogos de interpretação, mas sim um elemento de seus momentos, os dois tratados anteriormente e o que vem a seguir.

\section{Narrativa e as negociações entre os jogadores "fora" do jogo}

$$
\text { (Daphne) - Eu continuo andando... }
$$

\footnotetext{
${ }^{6}$ No sistema de jogo utilizado por esse grupo, tirar 1 em uma dado de vinte lados (d20) sempre representa um fracasso, enquanto que tirar 20 sempre representa um sucesso.
} 
(Jorge) - O bárbaro tá vindo...

(Frederick) - Jorge, a gente começa a andar pra direção...

(Jorge) - Mas as minas continuaram.

(Thiago) - Mas eu não conheço pessoalmente ninguém dessas?

(Jorge) - Aí o menino grita "Senhorita Isobel, senhorita Isobel".

(Guilherme só para o Thiago) - Não, você conhece pô... Dali...

(Daphne) - "Sim, fulano?"

(Thiago) - Não, velho, olha só, eu conheço todo mundo da vila. Vocês dois não são da vila!

(Guilherme) - Eu sou da vila.

(Jorge) - "Será que você pode ajudar. O righ-tuata convocou essa senhorita e ela está se recusando a ir até a presença do senhor Cedric MacMahon".

(Guilherme só para o Thiago) - Eu tô indo com ela... Assim ó.

(Thiago) - Eu aceno pras duas. Faço assim.

(Frederick) - Você chama o nome de alguma das duas? Porque as duas estão indo de costas. Ou elas tão indo em direção a eles?

(Jorge) - Não, perpendicular. Eles tão aqui e vocês pra cá.

(Frederick) -Então ela não tá te vendo. Se não chamar não vai perceber não.

(Thiago) - "Senhora Alissah... Alissei... Ailish..."

Essa série de falas narra a tentativa de encontro de quatro personagens dos jogadores citados acima. Enquanto a narrativa central do jogo ia se desenrolando (o garoto de recados Broom Ashfield convocava os personagens a atender um chamado do lorde da cidade de Soubar, Cedric MacMahon), podemos observar também uma narrativa paralela entre os jogadores que sabem que devem se reconhecer por serem os protagonistas da "corrente causal unificada" de que fala Ryan. Essa narrativa se envolve com a narrativa do processo de construção dos personagens. Além dessas, há ainda a narrativa construída pelo falar dos jogadores no papel dos personagens, que vai ressignificando a narrativa central e a da construção dos personagens.

A narrativa paralela entre os jogadores ou "fora" do jogo procura não só dar vazão ao ininterrupto processo de criação dos personagens, como também articular elementos para a narrativa das falas dos personagens. Desse modo, os interesses dos jogadores ampliam ou abafam possibilidades que possam perturbar aquilo que pretendem representar com os personagens. Essa narrativa "externa", portanto, busca envolver a narrativa interna dos personagens, muito embora acabe todo o tempo atropelada por ela. Isso me parece, em algum sentido, próximo do perpétuo tropeçar da narrativa historiográfica naquilo que já não é, o passado.

Ainda assim, é fácil perceber os elementos elencados por Fludernik ou as condições concêntricas de Ryan no que é narrado nesse momento, como bem exemplificado acima. 


\section{Possibilidades}

Embora essa tenha sido uma análise breve e com poucos exemplos, acredito que conferiu visibilidade à questão da relação entre narrativa e jogos de interpretação. Longe de perceber que a narrativa se fragmenta em momentos apartados e soltos, a análise construiu o entendimento de múltiplas relações que se imbricam fortemente, podendo ser apenas separadas para fins interpretativos.

Usando as definições de Fludernik e Ryan ficou claro como os jogos de interpretação podem ser classificados como narrativas. Além disso, é interessante perceber como essas condições dão a ler os elementos dos jogos.

Acredito ser possível construir uma possibilidade de jogo de interpretação onde múltiplas vozes articulem a narrativa como em uma orquestra onde todos são regentes. Essa possibilidade parece fecunda, assim como um caminho para pensar que um desafio literário não precisa ser uma negação historiográfica, pois mais do que nunca a historiografia sente o peso de sua síndrome de cientificidade. Essa possibilidade também serve à história.

Sendo assim, além do que já vem sendo praticado nos últimos anos, onde os RPGs se tornaram uma técnica para o ensino de diversas disciplinas escolares, em especial, do ensino de história, como nos mostram algumas publicações ${ }^{7}$, é possível nos aventurarmos mais. Os jogos de interpretação e suas relações com a narrativa servem como um campo privilegiado para pensarmos as possibilidades das narrativas historiográficas, bem como suas dimensões metodológicas e epistemológicas, se trabalharmos com um entendimento amplo de cultura histórica. Como destaca Ana Elizabete Farias, "ao se trabalhar com a noção de cultura histórica a partir do ensino, entendemos que o conhecimento histórico deve ser orientado no sentido de indagar a relação dos sujeitos com os seus objetos de conhecimento" (FARIAS, 2010: 167). Desse modo, uma cultura histórica que envolve e é envolvida pela cultura escolar.

Todo o tempo desafiados pelas artes, pelas poéticas e pelos versos, os historiadores parecem temer não ter que ser o personagem que quiseram ser, sem perceber que a construção

\footnotetext{
${ }^{7}$ SANTOS, Renato P.; DAL'FARRA, Rossano André. "A Saga da Física: Um RPG para o ensino de História da Física". In: Revista NUPEM. Campo Mourão: Unespar, v. 5, n. 8, pp. 33-51, jan.-jun. 2013; PEREIRA, Priscilla. Construindo narrativas: o RPG "role playing game" no ensino de história. In: Anais do II Congresso Nacional de Educação. Campina Grande: 2015, disponível em: http://www.editorarealize.com.br/revistas/conedu/trabalhos/TRABALHO_EV045_MD1_SA5_ID8155 0809201 5151342.pdf. Acesso em 26 jan. 2016; IONTA, Marilda. "Vamos brincar de história?". In: Revista de História da Biblioteca Nacional. Rio de Janeiro: 19 set. 2007, disponível em: http://www.revistadehistoria.com.br/secao/educacao/vamos-brincar-de-historia. Acesso em 26 jan. 2016; BIZ, Manuela. "O ABC do RPG". In: Revista Nova Escola. São Paulo: Abril, ed. 214, ago. 2008, disponível em: http://revistaescola.abril.com.br/historia/fundamentos/abc-rpg-423044.shtml. Acesso em 26 jan. 2016.
} 
do personagem é um processo ininterrupto. Encarar o ofício do historiador - esse ofício de ser professor de histórias - e as narrativas que construímos como um jogo de interpretações pode não significar fracassar com os dados, mas sim desdobrar muito mais possibilidades.

\section{Referências bibliográficas}

ARAÚJO, Raony \& RAMALHO, Geber. Narrativa e Jogos Digitais: Lições do RPG de Mesa. Recife: UFPE, 2015.

BACHELARD, Gaston. "A Poética do Espaço". In: Os Pensadores XXXVIII. 1. ed. São Paulo: Abril Cultural, 1974.

BARROS, José D'Assunção. "Paul Ricoeur e a narrativa histórica". In: História, imagem e narrativas, n. 12, abril 2011, disponível em: http://www.historiaimagem.com.br.

BIZ, Manuela. "O ABC do RPG". In: Revista Nova Escola. São Paulo: Abril, ed. 214, ago. 2008, disponível em: http://revistaescola.abril.com.br/historia/fundamentos/abc-rpg-423044.shtml. Acesso em 26 jan. 2016.

BURKE, Edmund. Reflexões sobre a revolução em França. Brasília; UnB, 1997.

CARRARD, Phillipe. "The distinction of historiography: Dorrit Cohn and referential discourse". In: Narrative. The official Journal of the International Society for the Study of Narrative. Columbus, OH, v. 20, n. 1, 2012.

CERTEAU, Michel de. A invenção do cotidiano: artes de fazer. Petrópolis: Vozes, 2014.

CHARTIER, Roger. "Philosofie et histoire: un dialogue". In: BEDARIDA, F. L'Historie et le métier d'historien en France. Paris: 1995. . A história cultural. Lisboa: Difel, 1990.

FARIAS, Ana Elizabete. "Cultura histórica, ensino de história e múltiplos saberes". In: SÆEculum - revista de história, n. 22. João Pessoa: UFPB, jan. jun. 2010.

FLUDERNIK, Monika. An introduction to narratology. Londres: Routledge, 2009.

HARTOG, François. "A arte da narrativa histórica". In: BOUTIER, Jean \& JULIA, Dominique (orgs.). Passados recompostos: campos e canteiros da história. Rio de Janeiro: UFRJ/FGV, 1998.

HUTCHEON, Linda. Poética do pós-modernismo: história, teoria, fiç̧ão. Trad. Ricardo Cruz. Rio de Janeiro: Imago, 1991.

IONTA, Marilda. "Vamos brincar de história?". In: Revista de História da Biblioteca Nacional. Rio de Janeiro: 19 set. 2007, disponível em: http://www.revistadehistoria.com.br/secao/educacao/vamos-brincar-de-historia. Acesso em 26 jan. 2016.

LECOUTEUX, Claude. História dos vampiros: autópsia de um mito. São Paulo: UNESP, 2005.

LOPES, André P. L. "Considerações sobre historiografia e narrativa a partir da leitura de 'Peixe Grande"'. In: $\begin{array}{llllllll}\text { Oficina do historiador. Porto Alegre, } & \text { v. } & \text { 8, } & \text { n. } & 1, & 2015 .\end{array}$ MARX, Karl. O 18 brumário de Luis Bonaparte. Goiânia: UFG, 2015.

PEREIRA, Priscilla. "Construindo narrativas: o RPG "role playing game" no ensino de história". In: Anais do II Congresso Nacional de Educação. Campina Grande: 2015, disponível em: http://www.editorarealize.com.br/revistas/conedu/trabalhos/TRABALHO_EV045_MD1_SA5_ID8155_0809201 5151342.pdf. Acesso em 26 jan. 2016.

PIHLAINEN, Kalle. "Of closure and convention: surpassing representation through performance and the referential". In: Rethinking History. The Journal of Theory and Practice, Londres, v. 6, n. 2, 2002.

RICOEUR, Paul. A memória, a história, o esquecimento. Campinas: Ed. Unicamp, 2012.

\section{Filistorónias}


RYAN, Marie-Laure. "Toward a definition of narrative". In: HERMAN, David. The Cambridge companion to narrative. Cambridge: CUP, 2007.

SANTOS, Renato P.; DAL'FARRA, Rossano André. "A Saga da Física: Um RPG para o ensino de História da Física". In: Revista NUPEM. Campo Mourão: Unespar, v. 5, n. 8, pp. 33-51, jan.-jun. 2013.

SOIHET, Rachel et al. (orgs.) Mitos, projetos e práticas políticas: memória e historiografia. Rio de Janeiro: Civilização Brasileira, 2009.

STONE, Lawrence. "O ressurgimento da narrativa: reflexões sobre uma nova velha história". In: Past and Present, n. 85, nov. 1979, pp. 3 - 24.

VOVELLE, Michel. A Revolução Francesa explicada à minha neta. São Paulo: UNESP, 2007.

WHITE, Hayden. "An old question raised again: is historiography art or science? (Response to Iggers)". In: Rethinking History 4:3 (2000), pp. 391-406. 